\title{
UM OLHAR PARA O ESTADO DE CONSERVAÇÃO DOS SAMBAQUIS URBANOS DE JOINVILLE
}

\section{A LOOK AT THE STATE OF CONSERVATION OF JOINVILLE'S URBAN SHELL MOUND}

\author{
Ana Cristina Twardowsky ${ }^{1}$ \\ Dione da Rocha Bandeira ${ }^{2}$ \\ Sandra Pascoal Leite de Camargo Guedes ${ }^{3}$
}

\section{RESUMO}

Os sambaquis são morros artificiais cobertos por vegetação e foram construídos por povos pré - coloniais que habitaram o Brasil fazendo parte do patrimônio cultural arqueológico brasileiro. O presente estudo revisou o estado de conservação dos sítios arqueológicos do tipo sambaqui, existentes na área urbana de Joinville. Os critérios utilizados para reavaliar o estado de conservação dos sítios foram abrasão; erosão acelerada antropogênica; impacto humano direto, edificações, deposição de resíduos sólidos, destruição mecânica; os mesmos utilizados por Oliveira (2000). Foi constatado que a realidade dos sítios da área urbana não sofreu mudanças significativas em relação a destruição antropogênica, mecânica e deposição de lixo.

PALAVRAS-CHAVE: Patrimônio Cultural; Sambaqui; Conservação; Joinville.

\begin{abstract}
The shell mounds are artificial hills covered with vegetation and were built by pre-colonial peoples who inhabited Brazil as part of the Brazilian archaeological cultural heritage. The present study reviewed the conservation status of archeological sites of the sambaqui type, existing in the urban area of Joinville. The criteria used to reassess the conservation status of
\end{abstract}

\footnotetext{
${ }^{1}$ Mestranda em Patrimônio Cultural e Sociedade pela Universidade da Região de Joinville (UNIVILLE). Especialista em Tecnologias da aprendizagem pelo Instituto Federal de Santa Catarina (IFISC). Docente pertencente ao quadro de professores do Serviço Nacional do Comercio (SENAC). E-mail: crisrolo.senac@gmail.com

${ }^{2}$ Doutora em História pela Universidade Estadual de Campinas (Unicamp), Graduada em Ciências Biológicas e mestre em Antropologia Social pela Universidade Federal de Santa Catarina (UFSC). Professora da Pós-graduação em Patrimônio Cultural e Sociedade/PPGPCS, na linha Patrimônio, Ambiente e Desenvolvimento Sustentável e dos cursos de História e Biologia Marinha, e coordenadora do Laboratório de Arqueologia e Patrimônio Arqueológico/LAPArq da Universidade da Região de Joinville/Univille. Arqueóloga do Museu Arqueológico de Sambaqui de Joinville. E-mail: dionerbandeira@gmail.com

${ }^{3}$ Doutora, Mestre e Graduada em História pela Faculdade de Filosofia, Letras e Ciências Humanas da Universidade de São Paulo (USP) e pós-doutora em Museologia pela Universidade Lusófona de Lisboa. É professora e pesquisadora da Universidade da Região de Joinville, no curso de História e no Programa de Pós-Graduação em Patrimônio Cultural e Sociedade. Na mesma Universidade já exerceu os cargos de Diretora de Ensino, Pró-reitora de Pós-Graduação, Pesquisa e Extensão e de Coordenadora do Programa de Mestrado em Patrimônio Cultural e Sociedade. E-mail: sandraplcguedes@gmail.com
} 
the sites were abrasion; accelerated anthropogenic erosion; direct human impact, buildings, deposition of solid waste, mechanical destruction; the same ones used by Oliveira (2000). It was found that the reality of sites in the urban area has not undergone significant changes in relation to anthropogenic, mechanical destruction and waste disposal.

KEYWORDS: Cultural heritage; Shell mounds; Conservation; Joinville.

\section{INTRODUÇÃO}

Nos últimos anos numerosas pesquisas abordaram a ocupação humana no Brasil, antes da colonização. Alguns habitantes pré-coloniais eram pescadores-caçadores-coletores e ocuparam a costa brasileira deixando como marcas na paisagem, estruturas formadas principalmente por conchas e ossos de peixes, essas estruturas são conhecidas como sambaquis ${ }^{4}$. Entretanto, por muitos anos a ênfase das pesquisas estavam nas práticas de subsistência de povos sambaquianos e mesmo com todo o interesse nessas ocupações a pesquisa pouco evoluiu no país entre as décadas de 1950 e 1990 (GASPAR, 2000; KLOKLER et al, 2010). Desta forma os povos sambaquianos eram descritos como nômades e acreditava-se que subsistiam com a coleta de moluscos. Rompeu-se essa narrativa a partir de estudos da década de 90 que apontaram a pesca como principal atividade e a ingestão de peixes e não de moluscos como principal fonte de proteína alimentar. (FIGUTI,1993, BANDEIRA,1992).

Os sambaquis, levando em consideração sua altura, podem ser considerados verdadeiros monumentos, já que muitos atingem mais de 10 metros de altura e já estiveram associados à moradia, trabalho e sepultamentos de humanos, e foram definidos como espaços multifuncionais (OLIVEIRA, MENEZES 1991). Estudos atuais revelam ausência de evidencias de atividades domésticas, e que os depósitos que constituem os sambaquis caracterizam um tipo de arquitetura funerária (KLOKER, 2014, BIANCHINI, 2015, GASPAR et al, 2018) Fazem parte de um sistema cultural, com desenvolvimentos regionais específicos (GASPAR, 2000; TENORIO, 2004). E sua cultura material pode ser observada ao longo da faixa costeira e indicada por objetos elaborados por tecnologia lítica e óssea polida, além de diversos outros tipos de objetos (DEBLASIS, et al., 1998; TENÓRIO, 2004). Embora os sambaquianos tenham habitado toda a costa, algumas regiões apresentam um maior número de sambaquis.

\footnotetext{
${ }^{4}$ Do tronco linguístico Tupi: tamba $=$ concha $+\mathrm{Ki}=$ monte
} 
Um dos primeiros grupos humanos a viver na baía da Babitonga foi de pescadorescoletores-caçadores, conhecidos por sambaquianos, que tinham como habito construir montes, alguns monumentais, construídos predominantemente de conchas e areia, sendo que a intencionalidade para a sua estruturação é incerta [...] as construções não deveriam ter somente um sentido funcional, mas também simbólico (BANDEIRA, 2018, p.208)

A Baía Babitonga localizada no sul do Brasil, no litoral norte de Santa Catarina, configura-se como um dos estuários mais importantes do estado e é cercada pelos municípios de Araquari, Balneário Barra do Sul, Garuva, Itapoá, Joinville e São Francisco do Sul; e possui aproximadamente 150 sítios arqueológicos do tipo sambaqui, sendo que 42 desses sítios estão localizados no município de Joinville, conforme imagem 1.

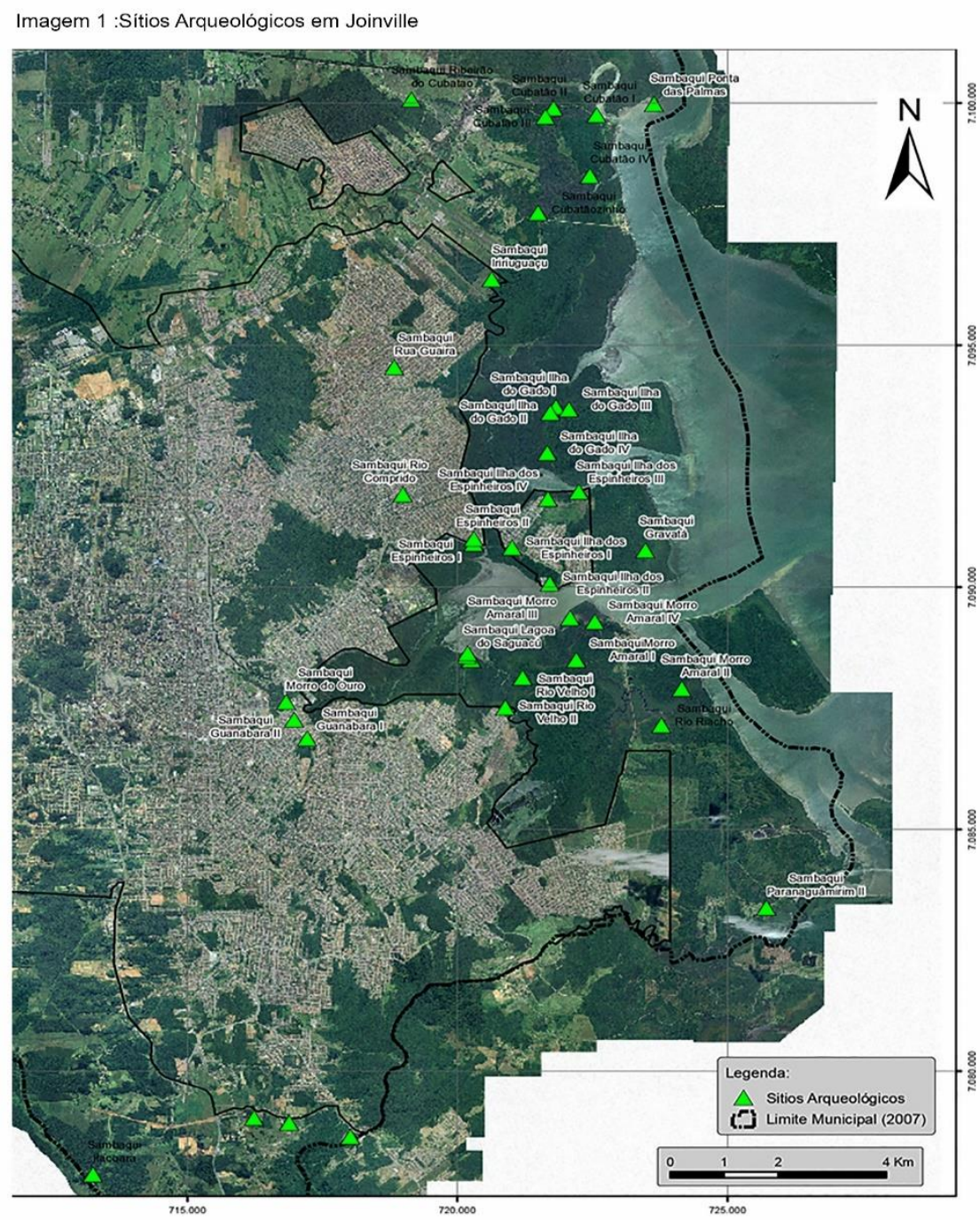

Fonte: Museu Arqueológico de Sambaqui de Joinville,2007 
A exploração dos sambaquis, iniciada pelos colonizadores portugueses, se deu em função das conchas, serem transformadas em cal pela ação do fogo. "As caieiras associadas aos sambaquis foram usadas como um recurso de obtenção de matéria-prima para produzir a cal, haja vista que era mais cômoda e prática a exploração devido a grande quantidade de sambaquis na região da Baía da Babitonga" (ZERGER, 2014, p.29). Essa cal seria utilizada na construção de casas, igrejas e pavimentação de ruas; tornando os sambaquis parte da vida econômica dos colonizadores.

\begin{abstract}
Nas décadas que se seguiram à conquista europeia, no século XVI, algumas das descrições feitas sobre a paisagem, bem como sobre os usos e costumes locais, incluíam referências aos montes de conchas que eram desmanchados e aproveitados no fabrico da cal, um elemento essencial ao sistema construtivo da época. Pelas propriedades aglomerantes, ela era utilizada como argamassa na edificação de igrejas, conventos, fortificações, casas etc. Por servir também como fertilizante, era ainda intensamente empregada na fabricação de adubos. Por seu lado, muitas conchas fragmentadas que compunham esses montes eram destinadas também à consolidação e pavimentação de estradas em terrenos arenosos. Sendo os sambaquis a única fonte conhecida de calcário no litoral, as caieiras - fornos rudimentares para a calcinação das conchas - tornaram-se a principal causa da sua destruição maciça. (LIMA, 1999/2000, p. 286).
\end{abstract}

E essa utilização durou até a década de 1960, levando à destruição total ou parcial de muitos desses sítios. (JOINVILLE, 2010).

A proposta deste trabalho é caracterizar os sambaquis de Joinville/SC a partir de uma perspectiva conservacionista dos sítios, fazendo uma avaliação em campo do estado de conservação dos sambaquis em área urbana, considerando-os como elemento da organização social dos pescadores-caçadores-coletores que habitaram a região entre 6.000 e 1000 anos antes do presente (AP) e que constituem herança cultural para a sociedade atual. Os critérios utilizados para avaliar o estado de conservação dos sítios foram os mesmos utilizados por Oliveira (2000), pretende-se com esse trabalho uma atualização dos resultados produzidos por este autor no que se refere aos sambaquis urbanos, averiguando-se o avanço dos problemas de conservação ocorridos nos últimos 20 anos. Para tanto foram realizadas visitas a campo para verificar a ocorrência nos sítios de:

a) Abrasão: "originalmente o termo abrasão referia-se a processos erosivos diretamente promovidos pelo mar" (OLIVEIRA, 2000, p.174), entretanto, usaremos para determinar as erosões causadas por "agentes exógenos externos como, águas fluviais e pluviais, ventos e alterações climáticas" (PARANÁ, 2019). 
b) Erosão acelerada antropogênica: seria a erosão causada pelo constante pisoteio, "a erosão acelerada antropogênica pode representar significativa destruição de material arqueológico.” (OLIVEIRA, 2000, p. 177)

c) Impacto humano direto, edificações. Para Oliveira "refere-se à construção, provisória ou não, de estruturas de habitação/acampamento e associadas, para as quais há a supressão da vegetação e destruição de porções do sítio arqueológico" (OLIVEIRA, 2000, p.178).

d) Impacto humano direto, deposição de resíduos sólidos: no Brasil, a maior parte das cidades já conseguiram solucionar o descarte de resíduos sólidos, contudo, muitas vezes, ainda são jogados em leitos de rios e em terrenos abandonados, esse tipo de descarte é frequente em alguns sítios. "Tem sido observado predomínio de lixo domiciliar, mesmo em áreas atendidas pelo sistema de coleta pública" (OLIVEIRA, 2000, p. 179).

e) Impacto humano direto, destruição mecânica. Oliveira (2000, p.179) esclarece que por destruição mecânica "considera-se toda ação humana, efetuada diretamente ou por meios de máquinas ou instrumentos diversos, que promovem esburacamento, desgaste, desagregação, remoção ou descaracterização das estruturas que compõem o sambaqui".

Os sambaquis em sua maioria são morros artificiais cobertos por vegetação, e podem ser encontrados em áreas litorâneas e fluviais. Em Santa Catarina os sítios podem ser monumentais, com mais de 5 metros de altura com maior quantidade de sepultamentos humanos e presença de zoólitos. (GASPAR et al, 2018; VILLAGRAN, 2013). No município de Joinville o sambaqui Ribeirão do Cubatão é um dos mais altos com aproximadamente 18 metros tendo sua área estimada em $3.500 \mathrm{~m}^{2}$ (JOINVILLE, 2010). Com relação às data de ocupação, pode haver variação existem sambaquis na Baia Babitonga que apresentam datação antigas, como o sítio Casa de Pedra "por volta de 6.000 anos AP" (BANDEIRA, et al, 2018, p.216), ou o Sambaqui Palmital de 5420 anos AP (JOINVILLE, 2010) Ocorrem também variações na composição dos sambaquis, além dos moluscos, peixes e sepultamentos em alguns ocorrem a presença de cerâmicas nas camadas superficiais.

Em 1961, passou a vigorar a Lei $\mathrm{n}^{\mathrm{o}} 3.924$ que dispões sobre os monumentos arqueológicos e pré-históricos (BRASIL, 1961). No artigo primeiro a Lei determina que a 
guarda e proteção do Patrimônio Arqueológico é realizada pelo poder público, de acordo com o artigo 175 da Constituição dos Estados Unidos do Brasil de 18 de setembro de 1946, constituição vigente na época (BRASIL,1946). A Lei contribuiu consideravelmente com o trabalho do órgão responsável pelo patrimônio, o Instituto do Patrimônio Histórico e Artístico Nacional (IPHAN), com a redução do uso inapropriado, vandalismo e saques aos sítios arqueológicos. Entretanto, mesmo com a evolução para uma Constituição Cidadã em 1988 e o aprimoramento das atuais leis, ainda é possível observar que principalmente nas áreas urbanas os sambaquis estão submetidos às mais diversas pressões antrópicas e de ação de agentes naturais como vento e chuvas, seja pela desinformação do cidadão ou especulação imobiliária. Contudo, a sociedade construtora de sambaquis nos deixou como herança parte de sua cultura material, sendo a principal e evidente aos nossos olhos, os próprios sítios arqueológicos.

\section{Estado de conservação dos sítios de Joinville}

Para averiguar as produções sobre os sítios arqueológicos do tipo sambaqui em Joinville, realizamos pesquisa voltada ao "estado da arte", que permite uma visão geral do que vem sendo produzido, possibilitando perceber a evolução das pesquisas, bem como as lacunas existentes. (ROMANOWSKI; 2006, p. 6).

Foram realizadas buscas na Scientific Electronic Library online (SciELO), nos Periódicos do Portal da Coordenação de Aperfeiçoamento de Pessoal de Nível Superior (Capes), no Business Source Complete information services (EBSCO) e no Google Acadêmico. Os vocábulos descritores utilizadas foram: conservação de sambaqui; sambaqui; conservação de sítios arqueológicos, e em inglês shell mound e conservation of archeological sites. Verificou-se que no portal SciElo dos 32 estudos encontrados, um é referente ao sambaqui Cubatão I que se localiza na área rural de Joinville; no portal da Capes dos 361 estudos identificados com os vocábulos descritores citados, encontram-se três estudos referentes ao sambaqui Cubatão I e dois referentes ao sambaqui Morro do Ouro, este localizado na área urbana do município. No EBSCO, não foram encontrados trabalhos com os vocábulos de busca. Os trabalhos sobre o Sambaqui Morro do Ouro estão relacionados ao cultivo de plantas do holoceno médio na costa da mata atlântica (PEZO-LANFRANCO et al, 2018) já os estudos que 
envolvem o sambaqui Cubatão I tratam dos peixes na alimentação de povos pré-coloniais (FOSSILE, 2014) e arqueobotânica (MELO JUNIOR et al, 2016)

Os trabalhos encontrados relativos a sambaquis tanto no portal SciElo, como no Portal da Capes, são voltados a assuntos relacionados a sambaquis e sambaquianos, como: moluscos utilizados na alimentação, ocupação humana antes da colonização, morfologia craniana dos sambaquianos, ovos de parasitas encontrados nas camadas arqueológicas, tecnologias usadas na pesca, plantas utilizadas, afinidades biológica entre grupos de sambaquianos, preservação do DNA, aplicabilidade da absorção de CO2, utilização de cetáceos, cultivo de plantas no holoceno, variação da paisagem, arquitetura funerária, artefatos líticos, taxonomia, descrição de fitólitos, datação por radiocarbono, datação por ressonância, dentre outros. Não foram encontrados trabalhos relacionados à conservação desses sítios arqueológicos na Scielo e no Portal da Capes.

Já no Google Acadêmico, encontramos dois estudos voltados à conservação e ou preservação com enfoque na musealização. De um modo geral o argumento é a especulação imobiliária que causaria impactos antrópicos, dificultando a conservação in situ, encontrando na musealização uma forma de valorizar e preservar a história. E dois trabalhos referentes a conservação de acervos, sendo que um deles é referente à conservação do acervo do Museu Arqueológico de Sambaqui de Joinville (MASJ). Apenas um trabalho estava voltado para a conservação in situ, Os Sambaquis da Planície Costeira de Joinville, Litoral Norte de Santa Catarina: Geologia, Paleogeografia e Conservação In Situ, dissertação de Mário Sérgio Celski de Oliveira em 2000. Além desse, não identificamos qualquer trabalho que abordasse a conservação in situ de sambaquis. Deve-se considerar que independentemente da ação antrópica os sítios arqueológicos estão sujeitos a processos naturais de degradação "um sítio arqueológico é composto por uma série de itens imersos em uma matriz de natureza geológica sujeita às mesmas ações e transformações existentes a qualquer outra matriz análoga na paisagem" (ARAUJO, 1995, p. 4). Portanto, este trabalho pretende focar os sambaquis da área urbana de Joinville, por sofrerem além das degradações normais, as oriundas de ações antrópicas em maior escala que os sambaquis localizados na área rural (OLIVEIRA, 2000), fazendo-se necessário estudos voltados à sua preservação e conservação.

Oliveira (2000, p. 239) realizou uma pesquisa sobre o estado de conservação dos sambaquis de Joinville no início dos anos 2000, e verificou que apesar de no Brasil as políticas 
públicas voltadas à preservação de sambaquis serem deficitárias, contudo, em Joinville o cenário é diferente. "Há concretas tentativas de preservação dos sítios por intermédio da intervenção do Poder Público".

Durante os anos de 2006 e 2007 a Prefeitura Municipal de Joinville, o Museu Arqueológico de Sambaqui de Joinville (MASJ) e a Fundação Cultural de Joinville, realizaram o Projeto Geoprocessamento Aplicado à Preservação dos Sambaquis em Joinville/SC (PGAPSJ). Desse projeto resultou o livro Joinville primeiros habitantes, elaborado por uma equipe de 17 pessoas e publicado em 2010.

O livro relata que os sambaquis Cubatão I, Cubatão II, Cubatão III, Cubatão IV e, Cubatãozinho, localizados na área rural, foram parcialmente danificados com o objetivo de aterrar estradas e o Cubatão I sofre com a erosão causada pela movimentação da maré; esse sítio foi objeto de estudos e escavações arqueológicas, que resultaram na identificação de sepultamentos, material faunístico e vegetal. Esclarece, ainda, que na área rural existem o Sambaqui Gravatá, que apresenta poucas informações, os sítios Ilha do Gado I, Ilha do Gado II, Ilha do Gado III, Ilha do Gado IV, só podem ser acessados por barco, o que dificulta os estudos e trabalhos referentes a eles. No Sambaqui Itacoara, também na área rural, que foi escavado em 1940 e em 2001, além dos sepultamentos foram encontrados diversos materiais confeccionados com rocha, como lâminas de machado e cerâmica.

Informa também que, igualmente na área rural, os sítios Morro do Amaral I, foi parcialmente destruído para construção de estradas; o Morro do Amaral II foi esfacelado provavelmente por caçadores de tatu, o Morro do Amaral III, sofre com a ação das marés e o Morro do Amaral IV não há informações. Os Sambaquis Paranaguamirim I, Paranaguamirim II, também não foram alvos de pesquisas. O Sambaqui Ponta das Palmas foi identificado em 1999 e o acesso é apenas por barco. Já o Sambaqui Ribeirão do Cubatão possui uma área estimada, em mais de $3.500 \mathrm{~m}^{2}$ e é um dos mais altos com 18 metros de altura. Degradações oriundas da construção de ranchos de pescadores e caçadores, bem como esburacamentos realizados por caçadores de tatu, assolam o Sambaqui Rio Bucuriúma, situado também na área rural. Recorrentemente degradados por pescadores e caçadores de tatu os sambaquis Rio das Ostras, Tiburtus e Rio Sambaqui só podem ser acessados por barco. O estreitamento do leito do rio que impede a navegação acaba por impossibilitar o acesso nos sambaquis Rio Fagundes, Rio Ferreira e, Rio Pirabeiraba que só podem ser alcançados por barco. Também de difícil 
ISSN 2238-7188

acesso e localização é o sambaqui Rio Riacho que fica no manguezal e tem o acesso por trilha. O acesso ao sítio Ilha dos Espinheiros III se dá por trilha que se inicia dentro de uma propriedade particular ou por barco, podemos considerar esse sítio como pertencente a área rural, e, portanto, sofre ações de abrasão.

Em sondagem aos sítios da área urbana de Joinville, no período de julho a setembro de 2019, foram levantados dados apresentados no quadro 1, que estão relacionados aos fatores de desgaste, que de um modo geral, "referem-se ao potencial destrutivo da ação humana como fator predominante na degradação de sítios arqueológicos" (OLIVEIRA, 2000, p.172).

Quadro 1- Fatores de degradação normalmente atuante nos sambaquis da área urbana de Joinville.

\begin{tabular}{|c|c|c|c|c|c|}
\hline Sambaqui & Abrasão & $\begin{array}{l}\text { Erosão } \\
\text { acelerada } \\
\text { antropogênica }\end{array}$ & $\begin{array}{l}\text { Destruição } \\
\text { mecânica }\end{array}$ & $\begin{array}{l}\text { Deposição } \\
\text { de } \\
\text { resíduos } \\
\text { sólidos }\end{array}$ & Edificação \\
\hline $\begin{array}{l}\text { Morro do } \\
\text { ouro }\end{array}$ & $\mathbf{x}$ & $\mathbf{x}$ & & $*$ & $0-\pi$ \\
\hline $\begin{array}{l}\text { Guanabara } \\
\text { I }\end{array}$ & $\mathbf{x}$ & $\mathbf{x}$ & & *Ж & $\mathbf{O}$ \\
\hline $\begin{array}{l}\text { Guanabara } \\
\text { II }\end{array}$ & $\mathbf{x}$ & & & & $\bullet$ \\
\hline $\begin{array}{l}\text { Ilha dos } \\
\text { espinheiros } \\
\text { I }\end{array}$ & $\mathbf{x}$ & $\mathbf{x}$ & & *Ж & \\
\hline $\begin{array}{l}\text { Ilha dos } \\
\text { espinheiros } \\
\text { IV }\end{array}$ & $\mathbf{x}$ & & & & $\bullet$ \\
\hline $\begin{array}{l}\text { Espinheiro } \\
\text { II }\end{array}$ & $\mathbf{x}$ & $\mathbf{x}$ & & & $\Xi$ \\
\hline \begin{tabular}{l|l} 
Rio \\
Velho II
\end{tabular} & $\mathbf{x}$ & $\mathbf{x}$ & $\pi(C)$ & $*$ & $\Lambda$ \\
\hline $\begin{array}{l}\text { Rua } \\
\text { Guaíra }\end{array}$ & $\mathbf{x}$ & & $\nearrow$ & $*$ & \\
\hline $\begin{array}{l}\text { Rio } \\
\text { Comprido }\end{array}$ & $\mathbf{x}$ & $\mathbf{x}$ & $\nearrow$ & $*$ & 0 \\
\hline \begin{tabular}{l|} 
Lagoa do \\
Saguaçu
\end{tabular} & $\mathbf{x}$ & $\mathbf{x}$ & & & $\Lambda$ \\
\hline \multicolumn{6}{|c|}{$\begin{array}{l}\text { Legenda } \\
- \text { (Passarela) } \\
\mathbf{x} \text { (Processos erosivos) } \\
\text { - (Cercas no entorno para proteção colocadas pelo proprietário) }\end{array}$} \\
\hline
\end{tabular}


O (cercas no entorno para proteção colocadas pelo poder público)

Ж (Resíduos de fogueira)

* (Lixo)

$\nearrow($ Esburacamento/ Vandalismo)

(C) (Remoção de conchas)

$\boldsymbol{\Lambda}$ (Casa)

$\boldsymbol{\pi}$ (Mirante)

$\boldsymbol{\Xi}$ (Alteração nas encostas para plantação )

Adaptação do quadro elaborado por Oliveira 2000, p.230.

O Sambaqui Morro do Ouro localiza-se próximo ao rio Cachoeira, em uma região movimentada da cidade, próximo a Ponte do Trabalhador no bairro Guanabara. O sítio sofreu algumas atividades antrópicas, como retirada de material para construção de estradas ou escavação arqueológica para construção da Ponte do Trabalhador, o que reduziu significativamente sua dimensão. As telas de proteção, colocadas pelo poder público, encontram-se deterioradas em alguns pontos, facilitando o descarte incorreto de lixos conforme ressalta a imagem 2 , entretanto, o sítio está bem conservado.

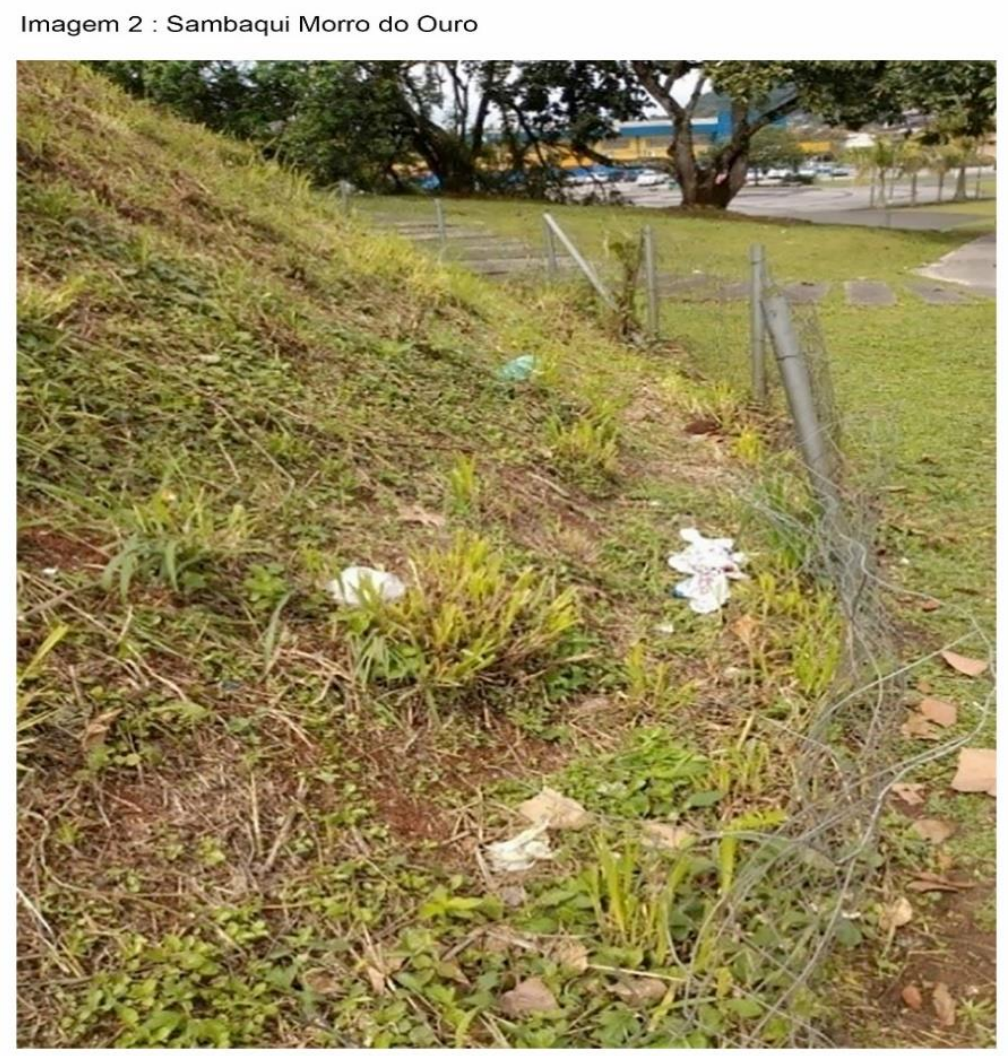

Fotógrafa: Sirlei Rolo

Fonte: acervo da autora, ago, 2019 
Em 2011, como demostrado no quadro 1 o sambaqui Morro do Ouro ganhou edificação, um mirante e uma passarela (imagem 3), que visa contribuir para a preservação do sambaqui no que se refere à erosão acelerada antropogênica, e permite ao público imaginar como seria a vista que os sambaquianos usufruíam há milhares de anos.

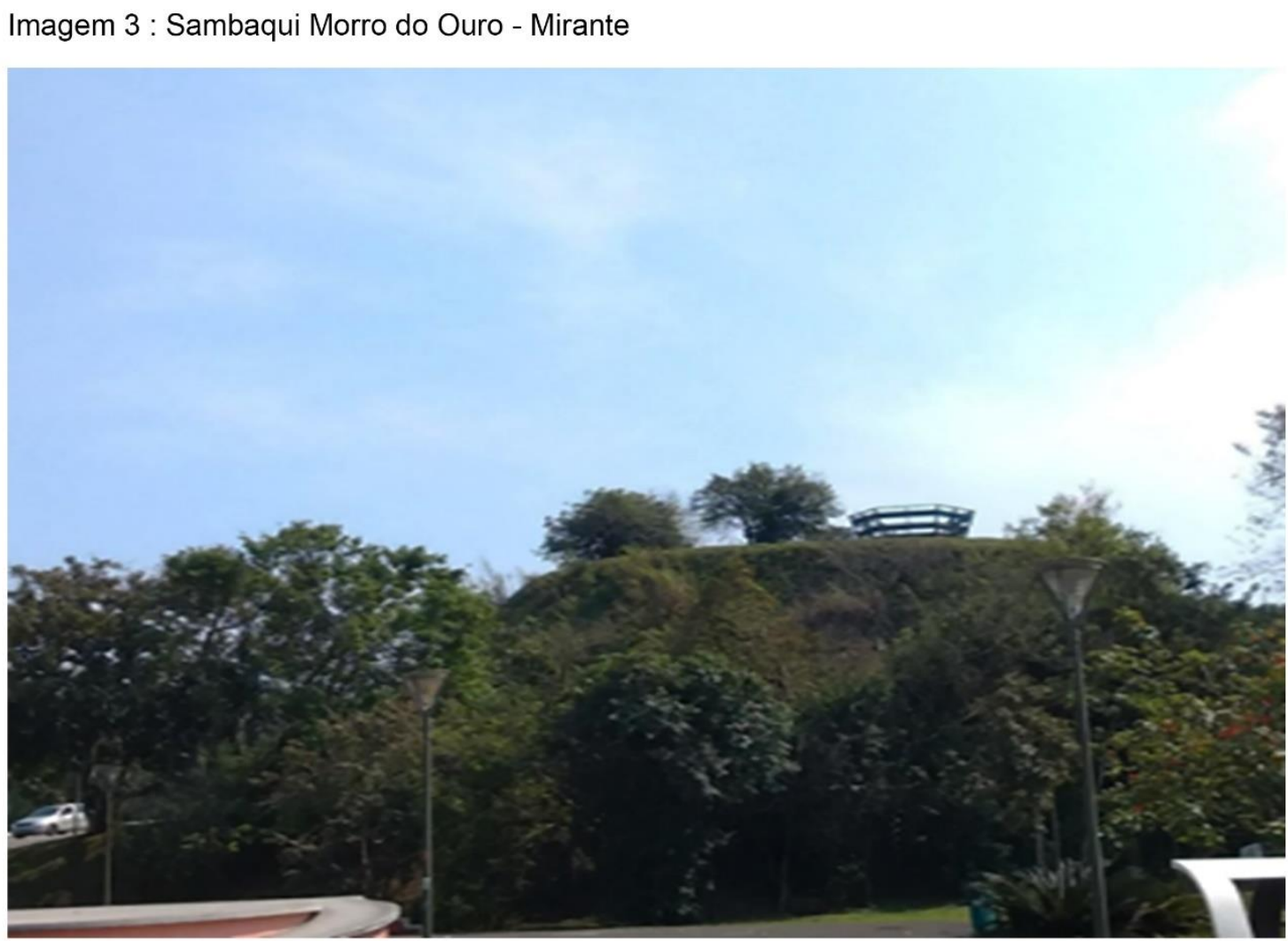

Fonte: acervo da autora, ago, 2019

Fotógrafa: Sirlei Rolo

Esse sítio passou por estudos e pesquisas. Entre 18 de julho e 10 de agosto de 2019 passou por escavação envolvendo as Universidades de York da Inglaterra, e Universidade da Região de Joinville-UNIVILLE, bem como o Museu Nacional do Rio de Janeiro, o Museu Arqueológico de Sambaqui de Joinville, entre outras. O objetivo da pesquisa foi verificar a presença de carboidrato na alimentação dos sambaquianos, envolvendo o cultivo de milho e cará, o resultado dessa pesquisa revelará se os sambaquianos além de serem pescadores, caçadores e coletores, se utilizavam de alguma técnica de cultivo.

Localizado em uma rua movimentada no bairro Guanabara, o sambaqui Guanabara I, também apresenta uma destruição parcial, causada pela urbanização. Uma das placas fixadas 
pelo projeto PGAPSJ está em bom estado de conservação, entretanto, ambas estão cobertas pela vegetação o que dificulta a leitura do conteúdo. A vegetação na parte posterior do sítio foi retirada pela ação antropogênica, o que contribui para que a abrasão seja mais intensa em relação a outros sítios. O sítio é usado para deposito de lixo (imagem 4) e apresenta restos de fogueira. O caminhar sobre o sítio não configura um problema, entretanto, as fogueiras, causam prejuízo à vegetação e ao sambaqui, ocasionando a destruição de material arqueológico.

Imagem 4 : Sambaqui Guanabara I

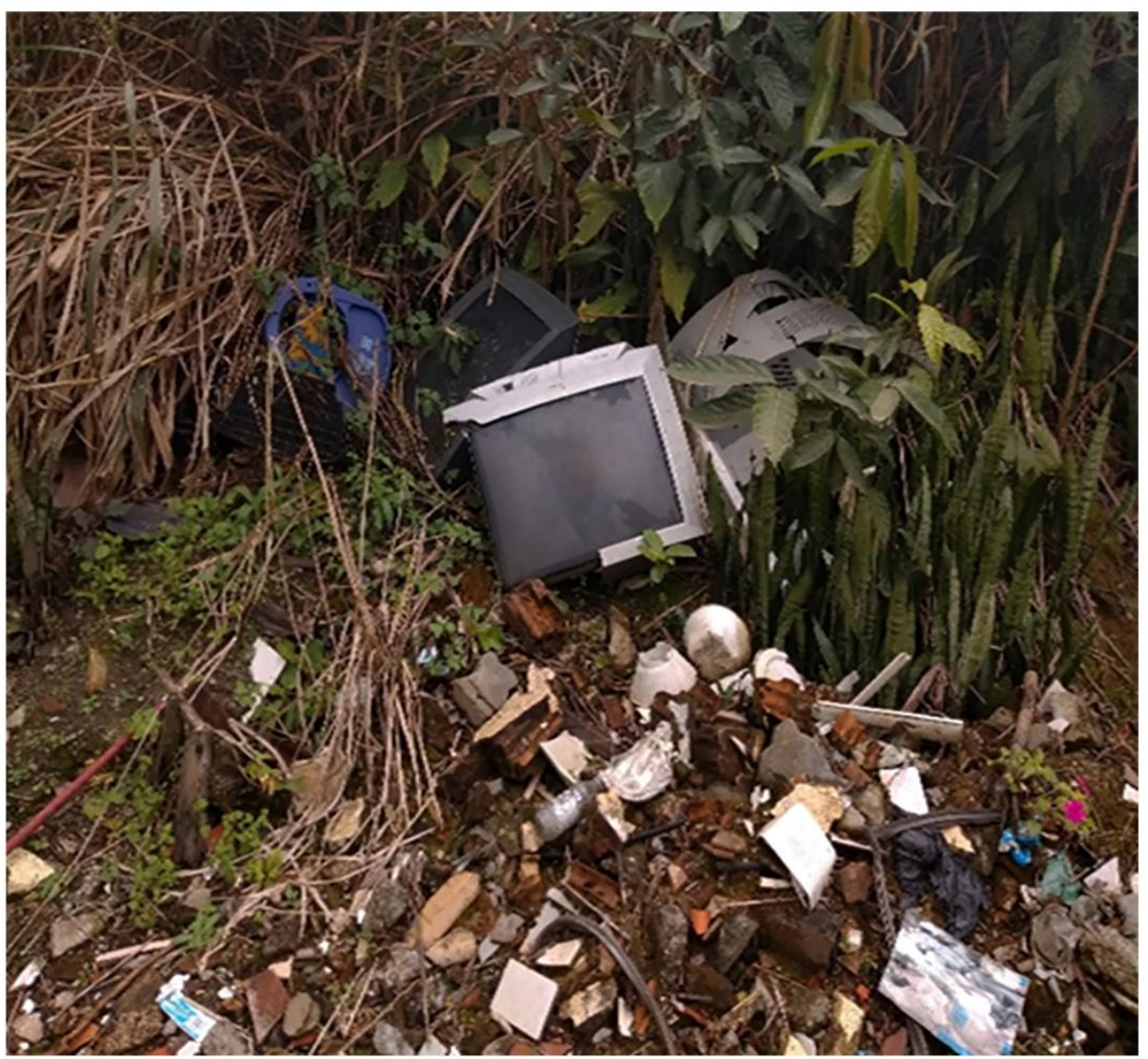

Fotógrafa: Sirlei Rolo

Fonte: acervo da autora, ago, 2019

O sítio Guanabara II encontra-se em propriedade particular, e portanto, foi possível apenas verificar que está guardado por cerca de proteção e que sofre abrasão como todos os outros sítios, não sendo possível verificar outros fatores de degradação por não ter sido localizado o proprietário.

Outro sítio que se localiza em propriedade particular é o Ilha dos Espinheiros II que, assim como todos os outros, foi parcialmente destruído e sofre ações de abrasão e erosão acelerada antropogênica. Está situado no Iate Clube de Joinville que atualmente mantem sua 
conservação, embora haja uma construção recente bem próxima ao sítio. Esse sítio faz parte do projeto Adote um sambaqui, implantado pelo MASJ em 1989.

\begin{abstract}
A preservação dos sítios arqueológicos foi uma das principais questões a ser estudada. Ficava evidente que não bastava vigiá-los e comunicar alguma ocorrência às autoridades [...]Assim, a curto prazo foi lançado o projeto "Adote Um Sambaqui", onde empresas privadas ou pessoas físicas poderiam colaborar com o município, protegendo um ou mais sambaquis. (GUEDES, 1991, p.114)
\end{abstract}

Também localizados em propriedades particulares estão os sambaquis Ilha dos Espinheiros III e IV. O sítio Ilha dos Espinheiros IV sofre abrasão relacionada à ação das chuvas, por estar próximo ao portão de acesso à propriedade é visível, entretanto, não é possível identificar a presença dos outros fatores de degradação elencados para a análise dos sítios da área urbana, por não ter sido possível localizar o proprietário.

Os sambaquis Ilha dos Espinheiros I, Rio Velho II e Rua Guaíra, além de sofrerem as destruições causadas pelos processos naturais de abrasão, hoje sofrem com o descarte inadequado de lixos, dentre eles os resíduos de construções. O fato das pessoas não conhecerem esses sítios como patrimônio contribuiu para a destruição do que resta deles, "porém, são esses vestígios que podem nos levar a conhecer o nosso próprio modo de ser enquanto espécie; podem nos ajudar a revelar a história da ocupação do continente sul-americano e em especial do Brasil" (CORTELETTI, 2008, p.9)

O sítio Rio Velho II, além do despejo de resíduos sólidos, sofre abrasão, erosão acelerada antropogênica. Além disso, são realizadas queimas de lixo sobre o sambaqui; algumas casas estão muito próximas ao sítio; serve de caminho para o rio homônimo e possui marcas da passagem de carros e barcos. Nota se, ainda, que foi feita a remoção de conchas, para que as embarcações tivessem melhor acesso à água.

O sambaqui Rua Guaíra, está em uma região muito urbanizada, a placa de identificação está encoberta pela vegetação e a população ao redor usa o espaço onde o sítio está como local para depósito de resíduos. A área mais afetada é o entorno do sítio, contudo alguns vestígios de resíduos podem ser encontrados no próprio sítio.

Já o sambaqui Espinheiros II passou por pesquisa de salvamento entre 1991 e 1992, quando foram removidas 32 casas que estavam sobre a área arqueológica e realizadas ações educativas com diversos segmentos, incluindo o ensino formal e as famílias atingidas; (JOINVILLE, 2010, p.44). 
Atualmente a vizinhança colocou sobre o sítio blocos de tijolos, que são utilizados para plantar flores e folhagens como a Espada de São Jorge, com o intuito de evitar a erosão, entretanto, a colocação desses blocos, pode ser considerada um fator de degradação porque pode movimentar o solo do sambaqui, alterando as estruturas presentes nas camadas. Não foram constatados depósito de lixo. Sobre o sítio foi colocada também uma estrutura de madeira para que os pássaros pudessem se alimentar, o que pode ser considerado um tipo de edificação, contudo, apresenta-se em bom estado de conservação. Essas ações da vizinhança possuem o intuito de proteger o sítio, todavia podem levar a degradação. O bairro está passando por ações de calçamento das ruas e o entorno do sítio está passando por pavimentação.

O Sambaqui Rio Comprido localizado no Bairro Comasa fica anexo a Praça David da Graça, que tem quadras de esporte, academia da terceira idade, parquinho e serve para a comunidade como área de lazer e um espaço para a prática de exercícios. Conforme relatado no Livro Joinville Primeiros Habitantes esse sítio foi descoberto durante escavações para abertura de ruas que iriam compor um conjunto habitacional, que visava abrigar funcionários da Fundição Tupy S/A, que contratou a empresa responsável para a construção e que constatou a presença do sítio. Assim que o sítio foi identificado, a empresa investiu em uma pesquisa de salvamento arqueológico que resultou em uma importante coleção arqueológica que está sob a guarda do Museu Arqueológico de Sambaqui de Joinville. (JOINVILLE, 2010). Podemos observar alguns fatores de degradação elencados no quadro 1, como deposição de resíduos sólidos (lixo).

Diferentemente do sambaqui Espinheiro II, o sambaqui Rio Comprido não encontra na vizinhança cuidados relativos à sua conservação. Contudo, também foi alvo de ações educativas com parceria estabelecida entre o MASJ e a Escola Municipal do bairro Dom Jaime de Barros Câmara, diversos projetos foram realizados, tendo como palco, o sambaqui e uma delas inclusive foi reconhecida através do Prêmio Embraco de Ecologia nos anos 1997 e 1998. (JOINVILLE, 2010).

O sambaqui Lagoa do Saguaçú (imagem 4), localiza-se à beira da lagoa do Saguaçú, foi intensamente explorado para a fabricação da cal. (JOINVILLE, 2010) 
Imagem 5: Sambaqui Lagoa do Saguaçú

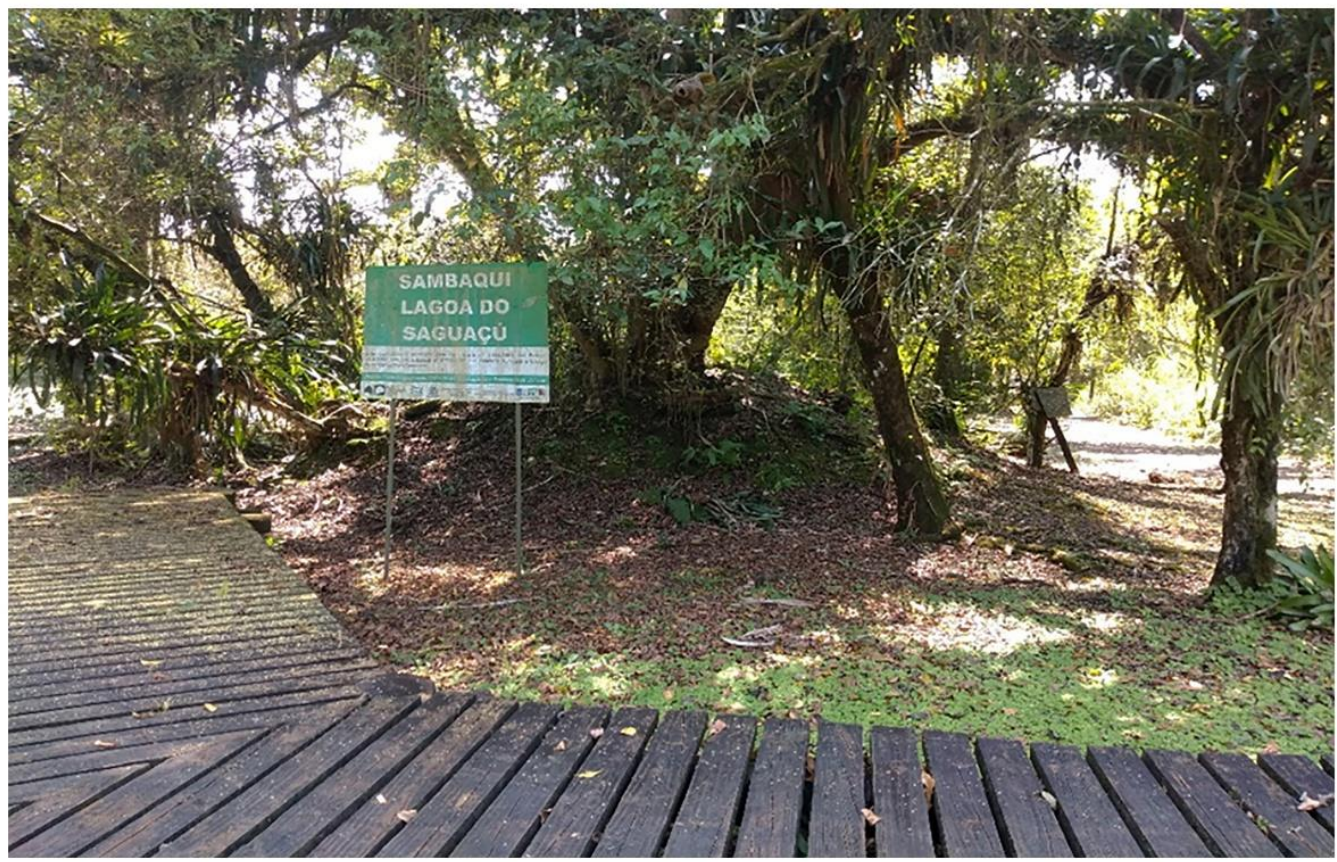

Fotógrafa Sirlei Rolo

Fonte: acervo da autora, ago, 2019

A área foi transformada no Parque Municipal Caieira, onde é possível observar as ruínas da antiga fábrica e "um conjunto de estruturas históricas, naturais e arqueológicas, difíceis de serem encontradas num só local e com um relativo estado de conservação que permite a fruição pública." (JOINVILLE, 2010, p.74)

O parque é bem cuidado, e possui vigilantes o que inibe ações que possam causar prejuízos às estruturas históricas. Entretanto, sofre os desgastes exercidos pela natureza, como chuvas fortes, ventos e a intervenção humana, como o simples andar sobre o sítio.

Mesmo em se tratando de pisoteamento realizado por seres humanos, na medida em que não constitui uma atividade intencional, como seria o caso do enterramento deliberado de artefatos, ou da remoção de peças com o intuito de limpar o solo. Os efeitos do pisoteamento humano nos solos arqueológicos foram discutidos por alguns autores, que realizaram experiências de pisoteamento (COURTIN \& VILLA, 1982; GIFFORD-GONZALEZ et al., 1985; NIELSEN, 1991; STOCKTON, 1973). Chegou-se à conclusão de que as peças podem sofrer dispersão vertical significativa, principalmente quando se trata de solos arenosos ou pouco coesos. (ARAUJO,1995, p.13) 
O Parque Natural Municipal Caieira é uma área de preservação ambiental e arqueológica de Joinville e foi criado pelo Decreto Municipal $n^{\circ} 11.734$ de 2004, e teve seu tombamento no mesmo ano.

\section{CONSIDERAÇÕES FINAIS}

Os sambaquis guardam grande parte da história pré-colonial do Brasil, sua cultura material pode ser encontrada por toda costa, entretanto algumas regiões como Joinville possuem um número considerável desses sítios que serviam como espaços multifuncionais. Alguns projetos, pesquisas e escavações já foram realizados, entretanto, ainda há muito que se estudar sobre os povos construtores de sambaquis. Contudo, para que isso ocorra é necessária a participação da sociedade na conservação in situ, já que se observa fatores de degradação em todos os sítios, como abrasão, erosão acelerada antropogênica, destruição mecânica, deposição de resíduos sólidos e edificações, conforme elencado no quadro1.

A degradação por abrasão é comum a todos os sítios em se tratando de águas pluviais, vento e sol. Em relação à erosão acelerada antropogênica, a maior incidência ocorre nas trilhas ou em locais onde a permanência de pessoas é mais intensa. Oliveira (2000) ao analisar os sítios urbanos observou esse tipo de erosão nos sítios Morro do Ouro, Guanabara I e II, Espinheiro II, Rio Velho II, Rio Comprido. O impacto humano pode interferir na erosão, um exemplo seria o sambaqui Rio Velho II, entretanto, o ser humano pode contribuir para a conservação dos sítios arqueológicos, como no sambaqui Morro do Ouro com a edificação de passarela e mirante, que contribuíram para a redução do impacto humano. Entretanto, os demais sítios continuam como o mesmo tipo de erosão que Oliveira encontrou há 19 anos.

Em relação à destruição mecânica, Oliveira já constatava que os sambaquis Morro do Ouro, Rua Guaíra, Espinheiro II, Rio Velho II, Rio Comprido e Guanabara II apresentavam esburacamentos e vandalismos, atualmente esse tipo de destruição mecânica é observada nos sambaquis Rio Velho II, Rua Guaíra e Rio Comprido, como revela o quadro 1. Nos demais sítios não foram observados esses fatores de degradação. A deposição de resíduos que era comum na maioria dos sambaquis urbanos nas pesquisas de Oliveira, ainda persiste.

No que se refere a edificações, as mais comuns foram as telas de proteção colocadas pelo poder público e as cercas (muros, grades etc.) colocadas pelos proprietários. Oliveira não 
havia identificado esse tipo de edificação em sítios urbanos. Esse tipo de proteção não se revelou eficaz nos espaços públicos, já que muitas telas foram retiradas e os despejos e ações antropogênicas continuaram. Permitir o acesso às pessoas, como ocorre nos sambaquis Morro do Ouro e Lagoa do Saguaçu, onde foram construídas passarelas e pórticos pode ser uma boa alternativa.

A realidade dos sítios da área urbana não sofreu mudanças significativas em relação a destruição antropogênica, mecânica e deposição de lixo. Entretanto, podemos observar as intervenções do poder público que visam a preservação desses sítios.

\section{REFERÊNCIAS BIBLIOGRÁFICAS}

ARAUJO, Astolfo Gomes de Mello. 1995. Peças que descem, peças que sobem e o fim de Pompéia: algumas observações sobre a natureza flexível do registro arqueológico. Revista do museu de arqueologia e etnologia. v.5, pp.3-25, 1995.

BANDEIRA, Dione da Rocha. Mudança na estratégia de subsistência. O Síto Arqueológico Enseada I- Um estudo de caso. 1992. 119p. Dissertação (Mestrado em Antropologia Social) Universidade Federal de Santa Catarina, Florianóplis, 1992.

BANDEIRA, Dione da Rocha et al.Resultados preliminares da pesquisa no sambaqui sob rocha Casa de Pedra, São Francisco do Sul, Santa Catarina, Brasil. Boletim do Museu Paraense Emílio Goeldi Ciências Humanas, v13 n 1. Pp 207-225, jan/abr. 2018.

BIANCHINI, Gina Faraco. Por entre corpos e conchas: prática social e arquitetura de um sambaqui.2015. 200p. Tese (Doutorado em arqueologia). Universidade Federal do Rio de Janeiro/Museu Nacional. Rio de Janeiro, 2015

BRASIL.1946. [Constituição (1946)]. Constituição dos Estados Unidos do Brasil de 1946. Brasília, DF: Presidência da República, [2019]. Disponível em: http://www.planalto.gov.br/ccivil_03/constituicao/constituicao46.htm. Acesso em: 15 Ago.2019.

BRASIL.1988. [Constituição (1988)]. Constituição da República Federativa do Brasil de 1988.Brasília, DF: Presidência da República, [2019]. Disponível em: http://www.planalto.gov.br/ccivil_03/constituicao/constituicao46.htm._Acesso em: 15 Ago.2019.

BRASIL.1961. Lei $n^{\circ} 3.924$ de 26 de julho de 1961. Monumentos arqueológicos e préhistóricos. Brasília, DF: Presidência da República, [2019]. Disponível em: http://www.planalto.gov.br/ccivil_03/leis/1950-1969/13924.htm. Acesso em: !5 Ago. 2019. 
CORTELETTI, Rafael.Patrimônio Arqueológico de Caxias do Sul. Porto Alegre: Nova Prova, 2008.

DEBLASIS, Paulo; et al Some references for the discussion of complexity among the Sambaqui Moundbuilders from the Southern Shores of Brasil. Revista de Arqueologia Americana. New York, v.15, pp75-105, 1998.

FIGUTI, Levy. O homem pré-histórico, o molusco e o sambaqui: considerações sobre a subsistência dos povos sambaquianos. Revista do Museu de Arqueologia e Etnologia. São Paulo, v.3, pp. 67-80, 1993.

FOSSILE, Thiago. Peixes na Alimentação de Povos pré-Coloniais- Estudo Ictioarqueológico da Sambaqui Cubatão I. 2013. 86p.Trabalho de Conclusão de Curso (Graduação em Biologia), Universidade da Região de Joinville, Joinville, 2013.

GASPAR, Madu. Sambaquis: arqueologia do Litoral. Rio de Janeiro: Jorge Zahar Editora, 2000.

GASPAR, Madu. Et al. Corpos e Montes: arquitetura da morte e do modo de vida dos sambaqueiros. Revista Memorare Tubarão, v.5, n.1, pp.264-282, jan./abr. 2018.

GUEDES, Sandra Pachoal Leite de Camargo. et al. Um olhar museológico para a arqueologia: a exposição "pré-história regional" de Joinville (Santa Catarina). Revista do museu de Arqueologia e Etnologia, São Paulo, v1, pp.113-129, 1991.

IPHAN- INSTITUTO DO PATRIMÔNIO HISTÓRICO E ARTÍSTICO NACIONAL.2010 Sistema Nacional de patrimônio Cultural. Brasília, DF. Disponível em: http://portal.iphan.gov.br/pagina/detalhes/217 Acesso em: 08 de set.2019.

JOINVILLE 2004. Decreto $n^{\circ} 11.734$ de 11 de março de 2004. Prefeitura de Joinville, [2019] Disponível em https://www.joinville.sc.gov.br/publicacoes/documentacao-parque-naturalmunicipal-da-caieira/

JOINVILLE.2007. Fundação cultural; museu Arqueológico de Sambaqui de Joinville. Joinville: Mapa dos Sítios Arqueológicos em Joinville.

JOINVILLE.2010. Fundação cultural; museu Arqueológico de Sambaqui de Joinville. Joinville: Primeiros Habitantes. Itajaí: Casa Aberta Editora,2010.

JOINVILLE. 1969. Lei $\mathrm{n}^{\mathrm{o}} 1042$ de 22 de dezembro de 1969. Disponível em: https://leismunicipais.com.br/a/sc/j/joinville/lei-ordinaria/1969/104/1042/lei-ordinaria-n1042-1969-cria-o-museu-arqueologico-de-sambaqui-de-joinville Acesso em 10 maio.2019.

KLOKLER, Daniela; et al. Juntos na Costa: Zooarqueologia e Geoarqueologia de Sambaquis do Litoral Sul Catarinense. Revista do Museu de Arqueologia e Etnologia, v. 20, pp53-76, 2010.

KLOKLER, Daniela; DEBLASIS, Paulo. Were Sambaqui People Buried in the Trash?Archaeology, Physical Anthropology, and the Evolution of the Interpretation of 
Brazilian Shell Mounds. In: ROKSANDIC, Mirjana; SOUZA, Sheila Mendonça de; EGGERS, Sabine; BURCHELL, Meghan; KLOKLER, Daniela (eds.) The Cultural Dynamics of ShellMatrix Sites. University of New Mexico Press. Pp. 91-100, 2014

LIMA, Tania Andadre. Em busca dos Frutos do Mar: os Pescadores-Coletores do Litoral Centro-Sul do Brasil. Revista da USP. São Paulo, n44, pp 270-327, 1999/2000

MELO JUNIOR, João Carlos Ferreira; et al. Arqueobotânica de um Sambaqui sul-brasileiro: integrando indícios sobre o paleoambiente e o uso de recursos florestais. Boletim do Museu Paraense Emílio Goeldi Ciências Humanas. Belém, v11, n3, pp727-744, set./dez.2016.

OLIVEIRA, Maria Dulce Barcellos Gaspar de. Aspectos da organização social de um grupo de pescadores, coletores e caçadores: região compreendida entre a Ilha Grande e o Delta do Paraíba do Sul, estado do Rio de Janeiro. 1991. 373p. Tese (Doutorado em Arqueologia) Universidade de São Paulo, São Paulo.

OLIVEIRA, Mario Sergio. Os Sambaquis da planície costeira de Joinville, litoral norte de Santa Catarina: geologia, paleogeografia e conservação InSitu. 2000. 310p. Dissertação (Mestrado em Geografia) Centro de filosofia e Ciências Humanas, Universidade Federal de Santa Catarina, Florianópolis, 2000.

PEZO-LANFRANCO, Luis et al. Middle Holocene plant cultivation on the Atlantic Forest coast of Brazil? Royal Society Open Science. York,V.5 n. Ago. 2018.

ROMANOWSKI, Joana Paulin; ENS, Romilda Teodora. As pesquisas denominadas do tipo "Estado da Arte". Diálogos Educacionais. Curitiba, v. 6, n 19, pp 37-50, set/dez. 2006.

TENÓRIO, Maria Cristina. Identidade cultural e origem dos sambaquis. Revista do Museu De Arqueologia E Etnologia. São Paulo, n14, pp169-178, 2004.

VILLAGRAN, Ximena. O que sabemos dos grupos construtores de sambaquis? Breve revisão da arqueologia da costa sudeste do Brasil, dos primeiros sambaquis até a chegada da cerâmica Jê. Revista Do Museu De Arqueologia E Etnologia. São Paulo, n23, pp139-154, 2013.

ZERGER, Giomar Felipe. Caieiras de Araquari e entorno: inquietações de um Patrimônio. 2014. 149p. Dissertação (Mestrado em Patrimônio Cultural e Sociedade) Universidade da Região de Joinville, Joinville, 2014.

\section{Artigo recebido em: agosto/2021}

Artigo aceito em: dezembro/2021 